JOURNAL OF GEOPHYSICAL RESEARCH, VOL. 93, NO. C12, PAGES 15,701-15,714, DECEMBER 15,1988

\title{
THE ROLE OF VERTICAL CHEMICAL FRACTIONATION IN CONTROLLING LATE QUATERNARY ATMOSPHERIC CARBON DIOXIIE
}

\author{
Edward A. Boyle \\ Department of Earth, Atmospheric, and Planetary Sciences, Massachusetts Institute of Technology, Cambridge
}

\begin{abstract}
The $30 \%$ decrease in atmospheric carbon dioxide during glacial maxima must be driven by some change in the chemical circulation of the ocean. Here, a new model for late Quaternary $\mathrm{CO}_{2}$ variability is presented which resolves some problems occurring in previous models (including the timing of carbon dioxide response and changes in the oxygen content of the deep ocean). The primary driving factor in this model is a rearrangement of chemical distributions in the ocean whereby labile nutrients and metabolic $\mathrm{CO}_{2}$ are concentrated in deep waters rather than in intermediate waters as observed in the modem ocean. This new "bottom-heavy" chemical structure does not affect atmospheric carbon dioxide directly. Instead, $\mathrm{CO}_{2}$-induced acidity lowers the deep ocean carbonate ion concentration and temporarily increases carbonate dissolution rates. Oceanic alkalinity then rises until the deep ocean carbonate ion is restored to its steady state value. The resulting increase in oceanic alkalinity draws $\mathrm{CO}_{2}$ out of the atmosphere into the ocean. Alkalinity and atmospheric $\mathrm{CO}_{2}$ lag several thousand years behind the change in oceanic chemical structure; this delayed response is determined by the limited rate of continental weathering and deep ocean carbonate dissolution relative to the oceanic alkalinity inventory. It is proposed that characteristic deglacial and preglacial states of the ocean are leading factors driving glacial-interglacial climate changes. This concept reinterprets the carbon isotope contrast between surface water and deep waters $\left[\Delta \delta^{13} \mathrm{C}(\mathrm{P}-\mathrm{B})\right]$ as due to a shift of light metabolic carbon from intermediate waters into deep waters. The process is illustrated here by a simple equilibrium five box ocean model. The observed intermediatedepth nutrient depletion is not sufficient in itself to determine which of several possible mechanisms are operating, and some mechanisms are not as effective in changing atmospheric $\mathrm{CO}_{2}$ as others. The largest response is seen from deepening the regeneration cycle of organic carbon; the least response is seen from converting North Atlantic Deep Water into intermediate water.
\end{abstract}

\section{Introduction}

Polar ice core studies have shown that atmospheric carbon dioxide was 90 parts per million by volume (ppmV) lower during glacial maxima (190 ppmV) than during warmer periods (280 ppmV) [Barnola et al., 1983, 1987; Neftel et al., 1982, 1985, 1988; Oeschger et al. 1984, 1985]. Lower $\mathrm{CO}_{2}$ significantly contributes to glacial cooling [Hansen et al., 1984] and provides an inter-hemispheric climate link. Considerable controversy has arisen regarding the causes of decreased glacial $\mathrm{CO}_{2}$, although it is agreed that some alteration of the oceanic chemical, biological, and physical circulations must be reponsible. Broecker [1982a,b] examined numerous aspects of the glacial ocean and proposed

\section{Copyright 1988 by the American Geophysical Union.}

Paper number 88JC03021. 0148-0227/88/88JC-03021\$05.00 that an increase in the phosphorus content of the ocean (due to oxidation of organic matter on the continental shelves) resulted in more efficient operation of the "biological pump": which drives carbon dioxide into the deep ocean. His model was consistent with many observations available at the time. The most striking success of his analysis was the prediction that the carbon isotope contrast between surface waters and deep waters would be greater during glacial times. Shackleton et al. [1983] verified this effect through the analysis of fossil planktonic and benthic foraminifera $\left(\Delta \delta^{13} \mathrm{C}(\mathrm{P}-\mathrm{B})\right)$. But Broecker's model has since fallen from favor because (1) it appears that the carbon isotope contrast changes before sea level change (as recorded by fossil carbonate $\delta^{18} 0$ ) [Shackleton and Pisias, 1985] which argues against a link to shelf sediments; (2) the oceanic inventory of the nutrient analogue cadmium (Cd) does not record the large glacial increase required by Broecker's model [Boyle and Keigwin, 1985]; and (3) the continental shelves may not contain enough organic matter in any event [Broecker and Peng, 1986].

More recent models account for changes in the surface/deep $\mathrm{CO}_{2}$ contrast by increasing nutrient depletion in high-latitude surface waters. These models call on improved efficiency of the "biological pump" by reducing the polar "leak" created by upwelling deep ocean waters [Knox and McElroy, 1984; Sarmiento and Toggweiler, 1984; Siegenthaler and Wenk, 1984]. A more efficient high-latitude pump can be attained by altered ocean circulation patterns or enhanced levels of highlatitude biological activity. These new models do not envision a direct link to sea level, nor do they call upon whole-ocean increases in nutrients. Some evidence appears to contradict the prime assumption of these models. The nutrient-related properties $\delta^{13} \mathrm{C}$ and $\mathrm{Cd} / \mathrm{Ca}$ in Antarctic planktonic foraminifera do not indicate any such glacial polar nutrient decrease (Table 1, Figure 1, [Labeyrie and Duplessy, 1985]). These new models (as well as Broecker's original model) also predict that parts of the deep ocean should become anoxic during glacial times. This prediction is contradicted by the presence of glacial age fossil benthic organisms in sediments and continuously high sedimentary iodine/carbon ratios from these regions [Pedersen et al., 1988]. Possibly, the evidence is misleading (e.g., perhaps Antarctic planktonic foraminifera did not grow during times of bottom water formation). But this failure to confirm glacial polar nutrient depletion and anoxia leaves these models without verification of key premises.

Another discrepancy between the theories and models has emerged recently. Further detailed work on planktonic and benthic foraminifera suggest that $\Delta \delta^{13} \mathrm{C}(\mathrm{P}-\mathrm{B})$ was at its minimum about 10,000 years ago and that it has since risen to levels not much less than those observed in glacial maximum sediments [Mix and Shackleton, 1986; Curry and Crowley, 1987; D. Oppo and R.G. Fairbanks, personal communication, 1988]. Recent work on polar ice cores does not support this scenario for atmospheric carbon dioxide; it appears instead that $\mathrm{CO}_{2}$ has been consistently high during 
Table 1. Cd Data From the Top $4 \mathrm{~m}$ of Core MD80304

\begin{tabular}{|c|c|c|c|c|c|c|}
\hline $\begin{array}{l}\text { Depth, } \\
\text { cm }\end{array}$ & $\begin{array}{c}\mathrm{Cd} / \mathrm{Ca}, \\
\mu \mathrm{mol} / \mathrm{mol}\end{array}$ & s.d. & $\mathrm{n}$ & $\mathbf{r}$ & $\begin{array}{l}\delta^{18} 0 \\
\%\end{array}$ & $\begin{array}{l}\delta^{13} \mathrm{C} \\
\% 。\end{array}$ \\
\hline 5 & 0.089 & 0.013 & 3 & & 2.91 & 1.40 \\
\hline 10 & 0.084 & 0.012 & 3 & & 2.93 & 1.38 \\
\hline 20 & 0.064 & 0.001 & 2 & & 2.66 & 1.30 \\
\hline 30 & 0.062 & 0.005 & 3 & & 2.96 & 1.43 \\
\hline 40 & 0.072 & 0.001 & 2 & & 2.85 & 1.22 \\
\hline 50 & 0.063 & 0.003 & 3 & & 2.90 & 1.28 \\
\hline 60 & 0.064 & 0.006 & 3 & & 2.81 & 1.11 \\
\hline 70 & 0.068 & 0.002 & 3 & & 2.95 & 1.07 \\
\hline 80 & 0.120 & & 1 & 2 & 2.72 & 0.89 \\
\hline 90 & 0.099 & 0.030 & 3 & & 2.88 & 1.17 \\
\hline 100 & 0.112 & 0.018 & 3 & & 2.53 & 1.13 \\
\hline 110 & 0.081 & 0.007 & 3 & & 2.84 & 0.92 \\
\hline 120 & 0.060 & 0.004 & 2 & & 2.85 & 1.07 \\
\hline 130 & 0.068 & 0.003 & 3 & & 2.90 & 0.93 \\
\hline 140 & 0.074 & 0.003 & 3 & & & \\
\hline 150 & 0.048 & 0.011 & 3 & & 3.26 & 0.83 \\
\hline 160 & 0.056 & 0.019 & 3 & & 3.29 & 0.84 \\
\hline 170 & 0.058 & 0.001 & 3 & & 3.73 & 0.84 \\
\hline 180 & 0.051 & 0.009 & 3 & & 3.62 & 0.97 \\
\hline 190 & 0.045 & 0.001 & 2 & & 3.63 & 0.53 \\
\hline 200 & 0.080 & 0.019 & 5 & & 3.47 & 0.29 \\
\hline 210 & 0.073 & 0.014 & 3 & & 3.45 & 0.19 \\
\hline 220 & 0.038 & & 1 & & 3.67 & 0.22 \\
\hline 230 & 0.096 & & 1 & 1 & 4.46 & 0.53 \\
\hline 240 & 0.064 & & 1 & & 4.75 & 0.45 \\
\hline 250 & 0.065 & 0.008 & 2 & & 4.25 & 0.38 \\
\hline 260 & 0.054 & 0.003 & 2 & & 4.26 & 0.64 \\
\hline 270 & 0.055 & 0.006 & 3 & & 4.23 & 0.56 \\
\hline 280 & 0.059 & 0.014 & 2 & 1 & 4.09 & 0.57 \\
\hline 290 & 0.056 & 0.004 & 2 & & 4.14 & 0.52 \\
\hline 300 & 0.057 & 0.007 & 3 & & 3.32 & 0.39 \\
\hline 310 & 0.105 & 0.029 & 3 & & 4.09 & 0.55 \\
\hline 320 & 0.096 & 0.009 & 3 & & 4.10 & 0.51 \\
\hline 330 & 0.095 & 0.017 & 2 & 1 & 3.82 & 0.58 \\
\hline 340 & 0.091 & 0.012 & 3 & & 4.20 & 0.45 \\
\hline 350 & 0.087 & 0.027 & 3 & & 3.79 & 0.43 \\
\hline 360 & 0.043 & 0.010 & 3 & & 3.75 & 0.43 \\
\hline 370 & 0.096 & 0.009 & 3 & & 3.58 & 0.43 \\
\hline 380 & 0.082 & 0.016 & 2 & 1 & 4.01 & 0.33 \\
\hline 390 & 0.067 & 0.002 & 2 & & 3.94 & 0.84 \\
\hline 400 & 0.049 & & 1 & & 3.56 & 0.91 \\
\hline
\end{tabular}

Oxygen and carbon isotope data are from Labeyrie and Duplessy [1985]. n is the number of analyses in mean; $r$ is the number of samples rejected from the mean.

the last several thousand years [Barnola et al., 1987; Neftel et al., 1988]. As with the polar nutrient evidence, it is tempting to blame this discrepancy on the data: perhaps the ice core time scale is wrong, or perhaps foraminifera (especially planktonic foraminifera) do not record $\Delta \delta^{13} \mathrm{C}(\mathrm{P}-\mathrm{B})$ reliably. While it is possible that the observations are flawed by some as yet unappreciated problem, we should first examine whether it is possible to devise a model that can accommodate the observations.

This paper will describe a new model for glacial $\mathrm{CO}_{2}$ which builds upon insights achieved in previous work but can account for a significant proportion of changes in glacial atmospheric $\mathrm{CO}_{2}$ without discounting observations. This model relies heavily on the "carbonate ion response" noted by Broecker [1982a,b] and discussed in more detail by Broecker and Peng [1987]. The origin of the carbonate response in this new model is novel, however, in that it does not assume shelf phosphorus transports nor does it assume altered polar preformed nutrient levels. Instead, the carbonate response in this new model arises from a shift of metabolic $\mathrm{CO}_{2}$ from intermediate depths of the ocean into the deeper waters of the ocean. The model accounts for some observations which previously have been considered problematical or irrelevant, and it makes some predictions which can be tested by new observations.

\section{Evidence for Reorganization of Intermediate/Deep $\mathrm{CO}_{2}$ Fractionation}

The model is based on the assumption that the oceanic distribution of dissolved carbon dioxide was shifted into a configuration where $\mathrm{CO}_{2}$ was concentrated in the deep waters relative to intermediate waters. Several lines of evidence support this premise. Boyle and Keigwin [1986, 1987] analyzed $\mathrm{Cd}$ and $\delta^{13} \mathrm{C}$ in glacial benthic foraminifera from cores representing the depth range $1700-4200 \mathrm{~m}$ in the western North Atlantic. These results show that glacial intermediate-depth North Atlantic was nutrient-depleted relative to today, and deeper waters were more nutrientenriched (Figure 2). The intermediate-depth nutrient depletion is equivalent to a decrease of about $0.6 \mu \mathrm{mol} / \mathrm{kg}$ in phosphorus. One of the shallow cores was from the open North Atlantic, but the smoking gun confirming Atlantic intermediate water nutrient depletion comes from cores in the Caribbean Sea. Because the Caribbean is rapidly flushed by intermediate-depth Atlantic water flowing over its sill, the nutrient content of deep waters from this basin reflects the nutrient content of Atlantic intermediate water. So the Caribbean has lower $\mathrm{Cd}$ and more positive $\delta^{13} \mathrm{C}$ during glacial times than during interglacial periods. Surprisingly, this observation languished unremarked in the literature for some time; the data appendix of the CLIMAP Project Members' [1984] "5e" study of the last interglacial included Caribbean $\delta^{13} \mathrm{C}$ data from glacial stage 6 and interglacial stage 5e showing the same result as for Boyle and Keigwin's stage 2/1 comparison. Also, Cofer-Shabica and Peterson [1986] have obtained a long Caribbean benthic $\delta^{13} \mathrm{C}$ record which showed that this pattern occurred repeatedly over the late Quaternary. Zahn et al. [1987] observe similar nutrient depletions from $\delta^{13} \mathrm{C}$ data from intermediate-depth cores in the Eastern Atlantic near Gibraltar. Some time after the aforementioned work, Oppo and Fairbanks [1987] obtained benthic $\delta^{13} \mathrm{C}$ from a high accumulation rate core which confirmed the results from the lower sedimentation rate cores of Cofer-Shabica and Peterson [1986)] and Boyle and Keigwin [1986, 1987]. More recently, N.A. Slowey and W.B. Curry (personal communication, 1988) have also documented the shallow nutrient depletion from $\delta^{13} \mathrm{C}$ data from two shallow $(<1000 \mathrm{~m})$ cores near the Bahamas. There can be little doubt that the glacial intermediate-depth North Atlantic was nutrient-depleted relative to modern waters at this depth and relative to deeper waters during glacial times.

The vertical nutrient profile in the Pacific is not yet as well known. The available results suggest that the intermediatedepth Pacific was also nutrient-depleted during glacial times. Shackleton [1985] first reported that Uvigerina in continental margin cores near the Sea of Okhotsk had higher $\delta^{13} \mathrm{C}$ values during glaciation. He suggested that this observation could be accounted for by hypothesizing bottom water formation in the North Pacific during glacial times. Nutrient depletion in these cores is confirmed by new Cd analyses from the same 

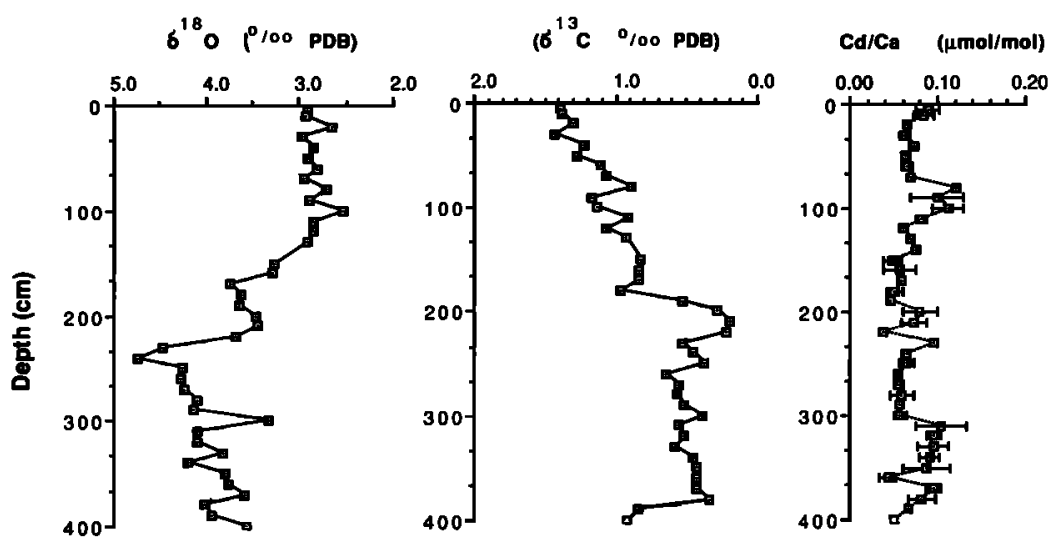

Fig. 1. Data from core MD80304 (51004'S,67044'E,1930 m). Oxygen and carbon isotope data are from Labeyrie and Duplessy [1985]. Picked samples of Neogloboquadrina pachyderma (left coiling) were kindly provided by L. D. Labeyrie. While there is some evidence for fluctuations in Cd, there is no systematic difference in the mean glacial and mean interglacial values (the preformed nutrient models predict a change of more than 0.05 in $\mathrm{Cd} / \mathrm{Ca}$ ). The glacial carbon isotope values are shifted from the Holocene values by more than the estimated change in mean $\delta^{13} \mathrm{C}$; i.e., it would appear from the surface $\delta^{13} \mathrm{C}$ that Antarctic nutrients were higher during glacial times (the opposite of the pre-formed nutrient model predictions).

core (Table 2, Figure 3). Evidence against the proposed bottom-water formation was provided by Keigwin [1987], who found a deep $(2980 \mathrm{~m}$ ) core from the North Pacific (with the reliable species Cibicidoides wuellerstorfi) that did not indicate any nutrient depletion during glacial times. Subsequently, Duplessy et al. [1988] obtained more extensive glacial Pacific core data (again, from Cibicidoides) which they interpreted to provide evidence that it was Pacific intermediate waters (above $2500 \mathrm{~m}$ ) which became more nutrient-depleted during glaciation. The glacial-interglacial carbon isotope shift suggested by their work is about $+0.4 \%$. More recently, Kallel et al. [1988] obtained data showing that intermediate waters in the northern Indian Ocean also were depleted in nutrients during glacial times. While the documentation in the Pacific is not as good as that in the North Atlantic and Indian oceans, and while there is little evidence as yet from the southern hemisphere, it is now plausible to hypothesize that metabolic chemicals are generally transferred from intermediate waters into deeper waters during glacial times.

\section{Why are Nutrients and $\mathrm{CO}_{2}$ Transferred from Intermediate into Deep Waters During Glacial Times?}

The new glacial $\mathrm{CO}_{2}$ distribution may have arisen in several ways. While these different mechanisms may be assigned different degrees of plausibility, there is no way at present to ascribe assign dominance to any of these mechanisms. It is possible that all contribute to some extent.

1. Boyle and Keigwin [1987] argued that nutrient-depleted North Atlantic winter surface waters formed less dense intermediate waters rather than deep waters during glacial times. This process would fill the upper Atlantic with nutrient-depleted waters, and some of this might extend into other ocean basins.

2. Oppo and Fairbanks [1987] used the evidence of Zahn et al. [1987] to argue that Mediterranean Water outflow increased substantially during glacial times. As with mechanism 1, this process would make the upper North Atlantic more nutrient depleted.

3. Boyle [1986] presented a model which demonstrated that increased low-latitude upwelling rates during glacial times would be expected to transfer nutrients from intermediate waters into greater depths. Each time nutrients are cycled into surface waters by low-latitude upwelling, there is a fixed chance (about 10\%) that organic debris will escape degradation during descent through the upper water column. Each time a phosphorus atom is cycled into the surface ocean, it has one more change to leak into the deep ocean. When the upper ocean cycles more frequently, metabolic chemicals concentrate themselves into the deep ocean.

4. It is possible that source waters for intermediate depth waters had a lower nutrient content than they do at present. Knox and McElroy [1984] suggested that higher light levels during summers could accomplish such an effect (although they actually were thinking of higher-latitude waters that form

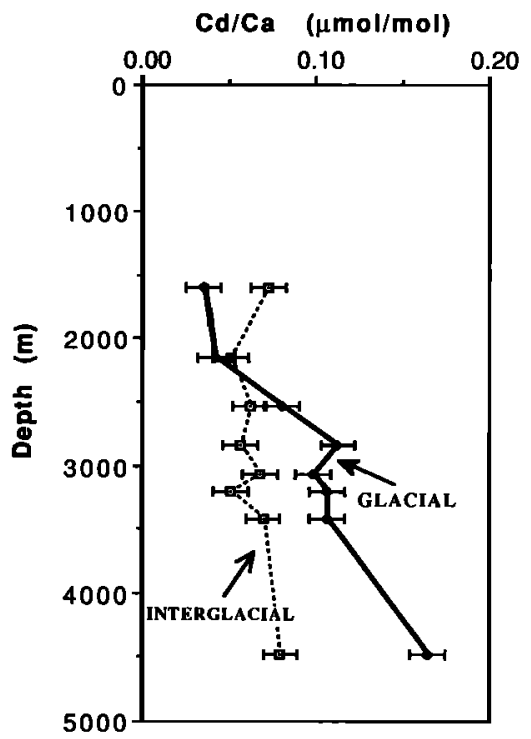

Fig. 2. Intermediate water nutrient depletion in the glacial Atlantic. Open squares are core top data; solid diamonds are from 18kyr core samples. Error bars are arbitrarily set at \pm 0.01 , which is a subjective estimate of the minimum reliability of the data based on numerous replicate analyses. 
Table 2. Data from Core v32-161

\begin{tabular}{|c|c|c|c|c|c|}
\hline $\begin{array}{l}\text { Depth, } \\
\text { cm }\end{array}$ & $\begin{array}{c}\mathrm{Cd} / \mathrm{Ca}, \\
\mu \mathrm{mol} / \mathrm{mol}\end{array}$ & s.d. & $\mathbf{n}$ & $\mathbf{r}$ & $\begin{array}{l}\delta^{18} 0, \\
\%\end{array}$ \\
\hline $\begin{array}{l}11 \\
16\end{array}$ & 0.169 & & 1 & & 3.66 \\
\hline 21 & & & & & 3.50 \\
\hline 31 & & & & & 3.49 \\
\hline 41 & & & & & 3.55 \\
\hline 45 & 0.167 & & 1 & & \\
\hline 51 & & & & & 3.45 \\
\hline 61 & & & & & 3.55 \\
\hline 66 & 0.206 & & 1 & & \\
\hline 71 & & & & & 3.68 \\
\hline 76 & 0.189 & & 1 & & \\
\hline 81 & & & & & 3.86 \\
\hline 87 & 0.127 & & 1 & & \\
\hline 101 & & & & & 3.89 \\
\hline 110 & & & & & 3.72 \\
\hline 116 & & & & & \\
\hline 121 & & & & & 3.95 \\
\hline 124 & & & & & \\
\hline 131 & & & & & 4.53 \\
\hline 136 & & & & & \\
\hline 141 & & & & & 4.77 \\
\hline 145 & 0.143 & 0.008 & 2 & & 501 \\
\hline 150 & 0.164 & 0.014 & 3 & & 5.01 \\
\hline $\begin{array}{l}155 \\
160\end{array}$ & & & & & 5.06 \\
\hline 165 & 0.143 & 0.004 & 3 & & \\
\hline 170 & & & & & 5.07 \\
\hline $\begin{array}{l}175 \\
181\end{array}$ & 0.143 & 0.014 & 3 & & 4.85 \\
\hline $\begin{array}{l}185 \\
190\end{array}$ & 0.140 & 0.017 & 3 & & 4.92 \\
\hline 196 & 0.104 & 0.024 & 3 & & \\
\hline 196 & 0.108 & & 1 & & \\
\hline 206 & 0.105 & 0.004 & 2 & & \\
\hline 210 & & & & & 4.81 \\
\hline 220 & 0.169 & & 1 & & \\
\hline 237 & & & & 1 & \\
\hline 243 & & & & & 4.45 \\
\hline
\end{tabular}

Oxygen and carbon isotope data from N.J. Shackleton (personal communication, 1987). $n$ is the number of analyses in the mean; $r$ is the number of samples rejected from the mean. Although most analyses were of Uvigerina spp., the sample at $196 \mathrm{~cm}$ includes a c. wuellerstofi analysis which agrees with the Uvigerina analysis (.104 average of 3 Uvigerina; .108 for $\underline{C}$. wuellerstofi).

bottom water). More recently, Martin and Gordon [1988] and Martin and Fitzwater [1988] suggested that iron is a limiting nutrient in the subpolar ocean and that increased dust fluxes during glacial times may have stimulated more biological activity. If this process occurred in the highernutrient water masses which form Pacific intermediate waters, it could account for nutrient depletion in the Pacific.

5. Some biologists and chemists who have studied the effect of productivity levels on particle fluxes (in daily- or weekly- variant upper-water-column regimes) argue that recycling of carbon is more efficient in times of low productivity than during those of high-productivity [Bishop et al., 1980]. If so, then an increase in the frequency of these high-productivity events would drive carbon more efficiently into the deep ocean; e.g. perhaps recycling only $80 \%$ of the organic matter in the upper $2500 \mathrm{~m}$, compared to about $90 \%$ at present. This change would transfer nutrients and metabolic $\mathrm{CO}_{2}$ into the deep ocean at the expense of the intermediate ocean.

Until we have more evidence, it will be difficult to assign any one of these mechanisms the dominant role. As will be seen, the effect on atmospheric $\mathrm{CO}_{2}$ of several of these mechanisms is similar, so it is possible to examine the consequences of this empirically observed phenomenom without understanding the primary cause. Nonetheless, if we are ultimately to acquire a predictive understanding of the process lowering glacial $\mathrm{CO}_{2}$, we will have to understand which specific mechanisms are operating.

\section{A Scenario for Glacial $\mathrm{CO}_{2}$}

This model for the transition from an interglacial high $\mathrm{CO}_{2}$ world to a low- $\mathrm{CO}_{2}$ glacial world assumes that there are two extreme states of ocean chemical distributions (see Figure 4). For reasons that will become apparent, these states are not considered "Interglacial" and "Glacial", but rather "Deglacial" and "Preglacial":

1. A new ocean circulation and biology regime emerges which alters the nutrient structure of the ocean, from a deglacial mode in which intermediate waters are nutrient-rich to a preglacial mode in which intermediate waters (above $2500 \mathrm{~m}$ ) are nutrient-depleted. $\mathrm{CO}_{2}$ and nutrients are transferred from intermediate waters into the deep waters; the total nutrient content of the ocean is constant.

2. As a result of this redistribution of light metabolic carbon from intermediate waters into deep waters, the carbon isotope contrast between surface and deep waters [ $\left.\Delta \delta^{13} \mathrm{C}(\mathrm{P}-\mathrm{B})\right]$ increases. The oxygen content of intermediate waters increases at the expense of lowered oxygen content of deep waters. Atmospheric $\mathrm{CO}_{2}$ is not affected directly by this change in chemical distributions.

3. Higher deep $\mathrm{CO}_{2}$ decreases the carbonate ion concentration $\left[\mathrm{CO}_{3}=\right]$ of the deep ocean. Decreased $\left[\mathrm{CO}_{3}=\right.$ ] results in higher carbonate dissolution rates in the deep sea and thereby creates an imbalance between carbonate input from continental weathering and output by deep sea sedimentation. The alkalinity of the ocean rises at a rate determined by the excess of continental supply relative to sedimentation and dissolution of carbonate sediments. The response time for this restoration is at least 2500 years and perhaps as long as 6000 years [Broecker and Peng, 1987; Boyle, 1983]. Hence the deep carbonate ion concentration is restored to its steady state value several thousand years after the initial change.

4. This increase in oceanic alkalinity lowers the $\mathrm{CO}_{2}$ partial pressure over the surface ocean. The $\mathrm{CO}_{2}$ content of the atmosphere approaches the new lower equilibrium value at the same rate as the alkalinity changes, i.e., several thousand years.

Similar reasoning applies to the transition from glacial to interglacial conditions. In this case, nutrients move from the deep ocean into the intermediate ocean, deep $\left[\mathrm{CO}_{3}=\right]$ increases, and there is there is an excess of carbonate sedimentation over input. The balance is restored with a response time of several thousand years, and the carbon dioxide content of the atmosphere increases.

Qualitatively, this scenario eliminates a number of discrepancies between observations and previous models for glacial $\mathrm{CO}_{2}$ :

1. $\Delta \delta^{13} \mathrm{C}(\mathrm{P}-\mathrm{B})$ changes several thousand years before atmospheric $\mathrm{CO}_{2}$ does, in accord with the observations. In 
V32-161 $48^{\circ} 17^{\circ} \mathrm{N} 149^{\circ} 04^{\prime} \mathrm{E} \quad 1600 \mathrm{~m}$
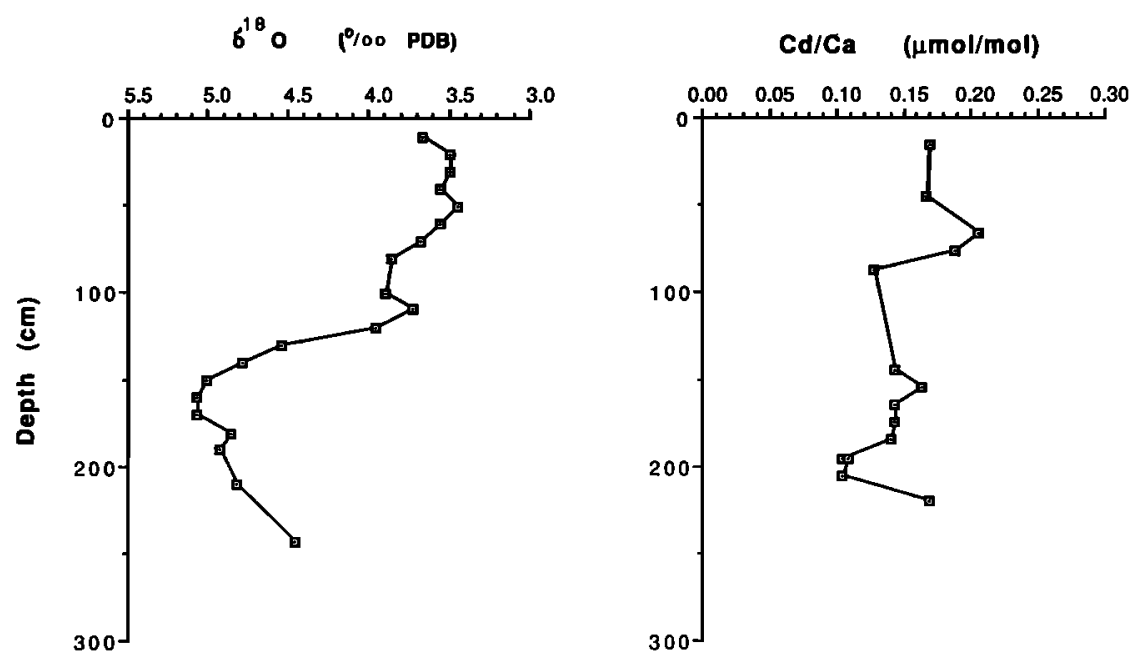

Fig. 3. Data from core V32-161, located on the continental margin of the Sea of Okhotsk, northeast Pacific ocean. Most samples were run in duplicate (see table 2). Note that the lowest values occur in the glacial section, particularly about $40 \mathrm{~cm}$ below the $\delta^{18} \mathrm{O}$ maximum. Highest values occur in the Holocene, particularly about $70 \mathrm{~cm}$ below the core top.
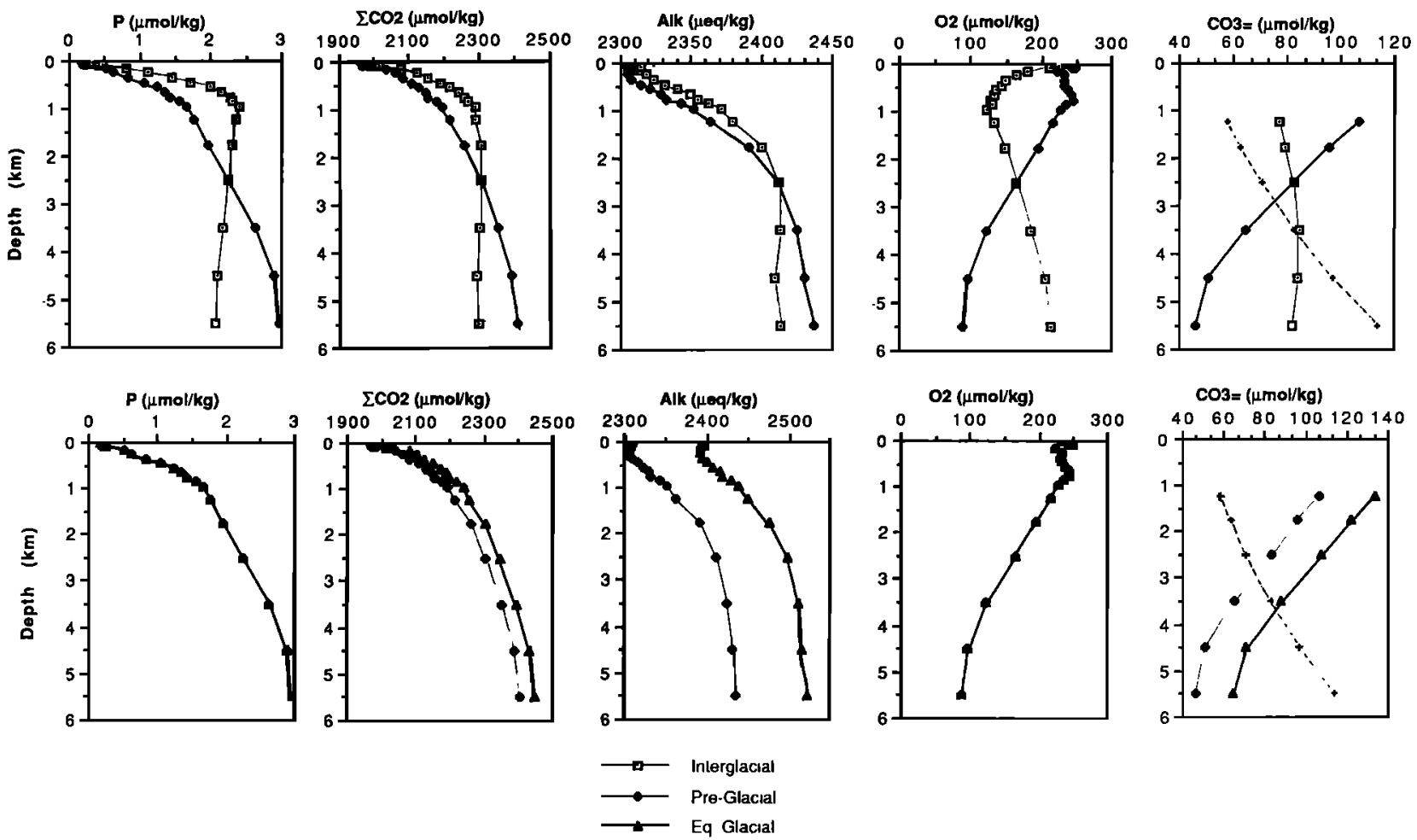

Fig. 4. Profiles illustrating the proposed changes occuring in the preglacial and equilibrium glacial ocean. (Top) comparison of modern (interglacial) ocean data from the Geochemical Ocean Sections Study (GEOSECS) (open squares) with proposed preglacial state of the ocean (solid diamonds), with a transfer of organic metabolites $\left(\mathrm{P}, \mathrm{CO}_{2}\right)$ from the intermediate depth ocean into the deep ocean. "Critical" (saturation) carbonate ion concentration indicated by crosses (dashed line). Note that the chemical rearrangement makes the deep ocean more undersaturated, so that the lysocline (the crossover point of the new $\left[\mathrm{CO}_{3}=\right]$ with critical $\left[\mathrm{CO}_{3}=\right]$ ) moves upward. This movement leads to higher rates of carbonate dissolution. (Bottom) comparison of proposed preglacial state of the ocean to the state attained when carbonate dissolution has restored the carbonate system to its steady state value. $\mathrm{P}$ and $\mathrm{O}_{2}$ are unchanged; $\mathrm{CO}_{2}, \mathrm{Alk}$, and $\left[\mathrm{CO}_{3}=\right]$ respond to carbonate dissolution. Note that the lysocline moves back to its original interglacial position. This movement restores carbonate dissolution rates back to the steady state level. 

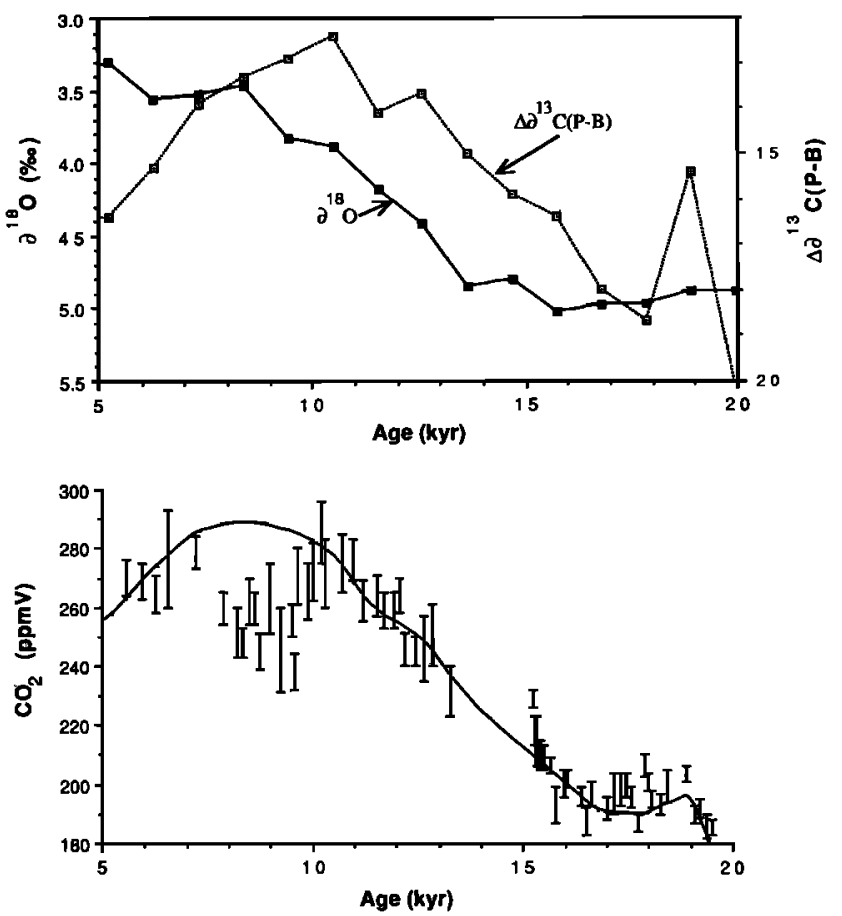

Fig. 5. Comparison of Byrd station $\mathrm{CO}_{2}$ data [Neftel et al., 1988] with V19-30 $\Delta \delta^{13} \mathrm{C}(\mathrm{P}-\mathrm{B})$ data. Raw $\Delta \delta^{13} \mathrm{C}$ data is shown at top, in juxtaposition with the $\delta^{18} \mathrm{O}$ data, showing the "lead" of $\Delta \delta^{13} \mathrm{C}(\mathrm{P}-\mathrm{B})$ relative to the $\delta^{180}$ response. At the bottom, the line shows arbitrarily-scaled output from using the V19-30 $\Delta \delta^{13} \mathrm{C}(\mathrm{P}-\mathrm{B})$ data as input into a linear equation with a $3 \mathrm{kyr}$ time constant. While the match is not perfect, the overall glacial to interglacial $\mathrm{CO}_{2}$ change occurs on a timescale that is consistent with the V19-30 $\Delta \delta^{13} \mathrm{C}(\mathrm{P}$ B) data input when put through the carbonate response model described in the text.

fact, the lag of $\mathrm{CO}_{2}$ relative to $\Delta \mathbf{\delta}^{13} \mathrm{C}(\mathrm{P}-\mathrm{B})$ is consistent with a time constant of several thousand years (Figure 5).

2. Antarctic nutrient concentrations need not change, hence there is no conflict with the planktonic $\delta^{13} \mathrm{C}$ and $\mathrm{Cd}$ data.

3. More oxygen remains in intermediate waters because of the depleted nutrient content. The oxygen minimum zone (which was thought to be most in danger of approaching anoxia) would have higher oxygen concentrations during glacial times, and aerobic benthic organisms would continue to deposit their shells.

As has been shown elsewhere [Boyle, 1988], the magnitude of the glacial-interglacial atmospheric $\mathrm{CO}_{2}$ change can be estimated if we assume that the deep box is homogeneous and that all sinking particulate biogenic matter degrades in "Redfield" proportions $106 \mathrm{CH}_{2} \mathrm{O}: 21 \mathrm{CaCO}_{3}$ : $16 \mathrm{~N}: 1 \mathrm{P}$.

$$
\begin{aligned}
\left(\mathrm{CH}_{2} \mathrm{O}\right)_{106}\left(\mathrm{NH}_{3}\right)_{16}\left(\mathrm{H}_{3} \mathrm{PO}_{4}\right)\left(\mathrm{CaCO}_{3}\right)_{21}+138 \mathrm{O}_{2} \\
= \\
+106 \mathrm{CO}_{2}+127 \mathrm{H}_{2} \mathrm{O}+\mathrm{H}_{3} \mathrm{PO}_{4}+16 \mathrm{NO}_{3}^{-}+16 \mathrm{H}^{+} \\
+21 \mathrm{CO}_{3}=+21 \mathrm{Ca}^{+}
\end{aligned}
$$

(This stoichiometry is not entirely appropriate, since the mean regeneration depth of calcium carbonate is deeper than that of organic carbon. This issue will be dealt with in a following section). For a given change in the deep phosphorus content
$(\Delta \mathrm{P})$, the deep total dissolved carbon dioxide $\left(\mathrm{\Sigma CO}_{2}\right)$ and alkalinity $(\triangle \mathrm{Alk})$ will initially change by

$$
\begin{aligned}
& \Delta \Sigma \mathrm{CO}_{2}=127 \Delta \mathrm{P} \\
& \Delta \mathrm{Alk}=(42-16) \Delta \mathrm{P}=26 \Delta \mathrm{P}
\end{aligned}
$$

and $\left[\mathrm{CO}_{3}=\right]$ will drop. To restore $\left[\mathrm{CO}_{3}=\right]$ to its initial value, $\Delta$ Alk $-\Delta \mathrm{CO}_{2}$ must be returned to zero by the addition of 2 equivalents of alkalinity for every mole of $\mathrm{CaCO}_{3}$ dissolved:

$$
\begin{aligned}
\Delta \mathrm{Alk}=26 \Delta \mathrm{P}+2 \Delta\left(\mathrm{CaCO}_{3}\right) & =26 \Delta \mathrm{P}+2(101 \Delta \mathrm{P}) \\
& =227 \Delta \mathrm{P} \\
\Delta \mathrm{CO}_{2}=127 \Delta \mathrm{P}+\Delta\left(\mathrm{CaCO}_{3}\right) & =127 \Delta \mathrm{P}+101 \Delta \mathrm{P} \\
& =228 \Delta \mathrm{P}
\end{aligned}
$$

When this deep ocean water upwells to the surface, Alk and $\mathrm{CO}_{2}$ are decreased by removal of biogenic debris:

$$
\begin{aligned}
& \Delta \text { Alk }(\text { surface })=\Delta A l k(\text { deep })-26 \Delta P \\
& =227 \Delta P-26 \Delta P=201 \Delta P \\
& \begin{aligned}
\Delta \mathrm{CO}_{2}(\text { surface }) & =\Delta \mathrm{CO}_{2}(\text { deep })-127 \Delta \mathrm{P} \\
= & 228 \Delta \mathrm{P}-127 \Delta \mathrm{P}=101 \Delta \mathrm{P}
\end{aligned}
\end{aligned}
$$

The expected new atmospheric $\mathrm{CO}_{2}$ content can be calculated by substituting these values into the thermodynamic equations for $\mathrm{pCO}_{2}$ of surface waters as a function of $\mathrm{\Sigma CO}_{2}$ and Alk (in this work the calculation was done according to the constants summarized by Millero [1979]).

The average change in intermediate water nutrient content appears to be about $0.6 \mu \mathrm{mol} / \mathrm{kg}$. The volume of the ocean above $2500 \mathrm{~m}$ is nearly equal to the volume below that depth [Menard and Smith, 1966], so deep ocean phosphorus must have increased by the same amount. According to (3), at steady state this change would increase the alkalinity of the ocean by $61 \mu \mathrm{eq} / \mathrm{kg}$; this alkalinity change is equivalent to a 54-ppmV drop in atmospheric $\mathrm{CO}_{2}$. Thus the magnitude of the $\mathrm{CO}_{2}$ change calculated in this fashion is about half of that observed in polar ice cores (about $90 \mathrm{ppmV}$ ). The residual might be due to underestimation of intermediate water nutrient depletion or perhaps due to contributions from other mechanisms.

One aspect of the ocean hydrography- $\mathrm{CO}_{2}$ system that bears noting is that the alkalinity response of the $\mathrm{CO}_{2}$ system integrates and minimizes short-term variability in ocean circulation. Since the circulation time of the ocean is under 1000 years, it is possible for the ocean to change its state in a relatively short time. Even if the ocean can change its state in less than a thousand years, the alkalinity lag smooths out these variations and acts as a stabilizing force on climate.

\section{Equilibrium Five-Box Model Illustration}

A simple 5-box model was constructed to illustrate the concept quantitatively. The goal of this model is to include the most relevant processes without introducing excessive complications. The following requirements dictated the structure of the model: (1) high-nutrient and low-nutrient polar surface boxes were included so that the preformed 


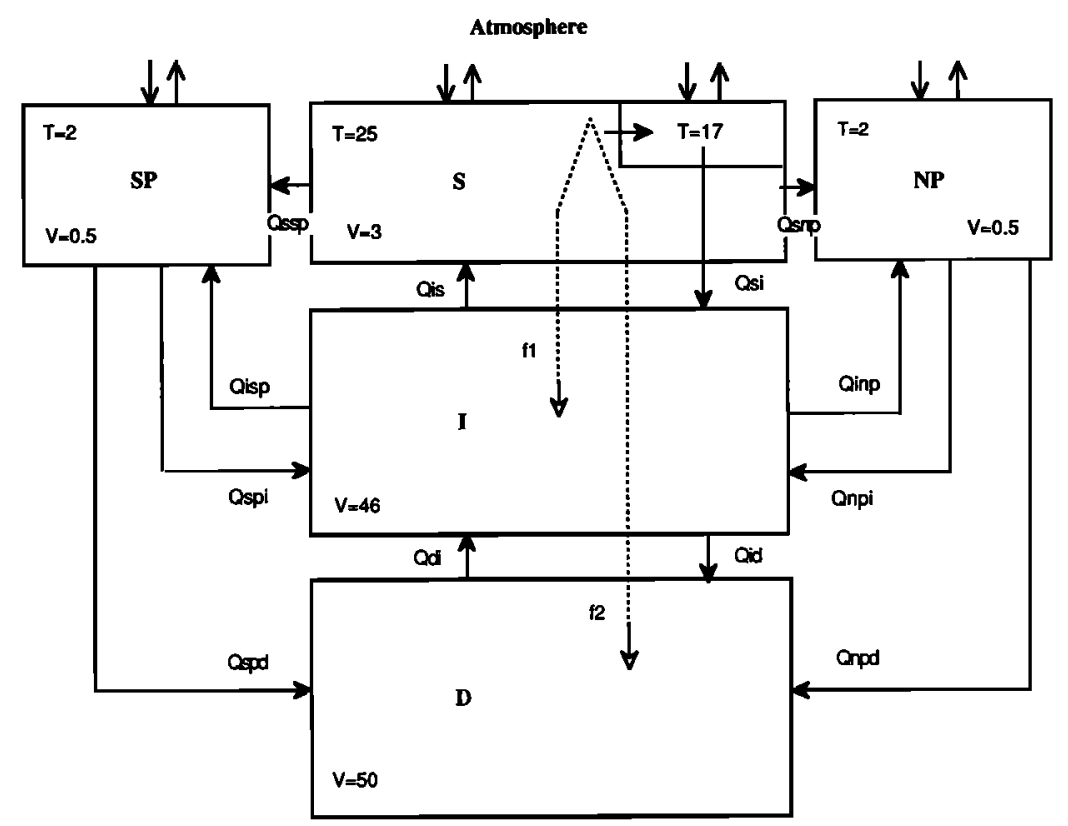

Fig. 6. Equilibrium box models for atmospheric $\mathrm{CO}_{2}$. Flows of water are indicated by solid arrows; equilibration between atmosphere and surface ocean is indicated by arrows and transfer of sinking particles is indicated by dotted line and open arrows. Relative volumes of boxes are indicated at in the bottom corner; temperature of gas equilibration is indicated in the top corner. SP, nutrient-enriched "south polar" box; NP, nutrient-depleted "north polar" box; $S$, warm surface box; I, intermediate box; $D$, deep box.

nutrient effects on $\mathrm{CO}_{2}$ could be controlled and so that advective sources of cold low- and high-nutrient water would be available, (2) separate intermediate and deep boxes were required to allow for variations in vertical nutrient fractionation, and (3) the warm surface ocean covers the largest portion of the surface area of the ocean, and hence must be included to account for gas exchange between the ocean and atmosphere. Model details are described in Appendix $\mathrm{A}$ and illustrated in Figure 6 . The model is intended to serve as a simple illustration of the above scenario, and there is no reason to defend the realism of the model as a complete and definitive description of the late Quaternary ocean. Some processes which are likely to be significant (such as the effect of forest/soil regrowth on carbon isotopes) are neglected deliberately to keep the model simple.

Inter-box fluxes in the equilibrium-interglacial models IG-1 and IG-2 (see Tables 3 and 4 and Figure 6) were adjusted to approximate modern oceanic distributions [Takahashi et al., 1981] and set to fill the ocean with new bottom water in 1000 years. There are many other possible solutions to the modern distributions, even given the restricted structure of this model. A particularly interesting case is discussed in Appendix B. There is a tradeoff between the deep carbonate regeneration parameter (i.e., the fraction of carbonate assumed to dissolve in the deep ocean) and the mixing rate between intermediate and deep ocean. These two cases are henceforward refered to as low-mixing and highmixing parameters. This tradeoff is illustrated in models IG-1 and IG-2, which have similar chemical distributions but assume quite different carbonate regeneration parameters and intermediate-deep mixing rate. It appears that the vertical distribution of alkalinity does not mandate a unique value for the percentage of carbonate that dissolves in the deep ocean, contrary to most current opinion [Edmond, 1974; Dymond and Lyle, 1985].
Equilibrium-glacial models (Tables 3 and 4) were modified from the equilibrium-interglacial glacial model to produce a specified vertical transfer of nutrients from the intermediate ocean into the deep ocean while keeping polar surface nutrient concentrations constant. This transfer was achieved in several ways:

G-1 and G-2: The vertical regeneration of organic matter was altered for more remineralization in the deep box. This change is the most effective way to alter atmospheric $\mathrm{CO}_{2}$, since it puts "pure" $\mathrm{CO}_{2}$ into the deep box and maximizes the alkalinity response. In this version, reduction of mean intermediate water phosphorus by $0.4 \mu \mathrm{mol} / \mathrm{kg}$ elicits a $\mathrm{pCO}_{2}$ reduction of $46 \mathrm{ppmV}$ (low mixing) and $41 \mathrm{ppmV}$ (high mixing). The response here does not depend much on assumed alkalinity regeneration parameters.

G-3 and G-4: The rate of intermediate water/warm surface water overturn (i.e., wind-driven upwelling) was increased in these trials. G-3 used "low mixing, low deep carbonate regeneration" parameters and G-4 used "high mixing, high deep carbonate regeneration" parameters. The same intermediate water nutrient depletion seen in the other glacial models was obtained in both trials, although a larger upwelling rate increased was needed in the "high-mixing" case G-4. In low-mixing G-3, $\mathrm{pCO}_{2}$ was reduced by 27 ppmV, whereas in high-mixing G-4, pCO only went down by $13 \mathrm{ppmV}$. If all carbonate regeneration occurs in the deep box, the $\mathrm{pCO}_{2}$ will actually increase. The enhanced upwelling mechanism cannot be as effective in reducing $\mathrm{pCO}_{2}$ as G-3 because of the additional deep alkalinity regeneration that accompanies the increase in surface carbonate productivity.

G-5: Here, the intermediate water nutrient reduction is achieved by changing most North Atlantic Deep Water (NADW) into North Atlantic Intermediate Water (NAIW) (low-mixing case only). This change reduces intermediate water phosphorus by $0.4 \mu \mathrm{mol} / \mathrm{kg}$, but $\mathrm{pCO}_{2}$ decreases by only $8 \mathrm{ppmV}$. Hence simple changes in the NADW 
Table 3. Variable Parameters Input to Box Model

\begin{tabular}{|c|c|c|c|c|c|c|c|}
\hline & IG- 1 & IG - 2 & $G-1$ & $G-2$ & G-3 & $G-4$ & $G-5$ \\
\hline $\mathbf{f}_{d}(\mathrm{Org})$ & 0.13 & 0.14 & 0.26 & 0.40 & 0.13 & 0.14 & 0.13 \\
\hline$f_{d}\left(\mathrm{CaCO}_{3}\right)$ & 0.27 & 0.42 & 0.27 & 0.42 & 0.27 & 0.42 & 0.27 \\
\hline$Q_{s-i}$ & 126 & 126 & 126 & 126 & 270 & 400 & 126 \\
\hline$Q_{\mathbf{i}-\mathbf{s}}$ & 159 & 159 & 152 & 152 & 296 & 426 & 152 \\
\hline$Q_{i-s p}$ & 28 & 28 & 38 & 38 & 28 & 28 & 29 \\
\hline$Q_{s p-i}$ & 16 & 16 & 19 & 19 & 9 & 9 & 10 \\
\hline$Q_{i-n p}$ & 11 & 11 & 16 & 16 & 16 & 16 & 15 \\
\hline$Q_{n p-i}$ & 16 & 16 & 21 & 21 & 21 & 21 & 36 \\
\hline$Q_{s p-d}$ & 20 & 20 & 20 & 20 & 20 & 20 & 20 \\
\hline$Q_{n p-d}$ & 20 & 20 & 20 & 20 & 20 & 20 & 4 \\
\hline$Q_{s-n p}$ & 25 & 25 & 25 & 25 & 25 & 25 & 25 \\
\hline$Q_{\text {s-sp }}$ & 8 & 8 & 1 & 1 & 1 & 1 & 1 \\
\hline$Q_{i-d}$ & 10 & 60 & 10 & 100 & 10 & 60 & 10 \\
\hline$Q_{d-i}$ & 50 & 100 & 50 & 60 & 50 & 100 & 34 \\
\hline
\end{tabular}

Water fluxes (Q) in sverdrups ( $\left.1 \mathrm{~Sv}-10^{6} \mathrm{~m}^{3} / \mathrm{sec}\right)$. For explan-

ation of model code, see footnote to table 4 .

ventilation are not an effective means to change atmospheric $\mathrm{CO}_{2}$. A decrease in intermediate water phosphorus is not in itself sufficient to elicit an atmospheric $\mathrm{CO}_{2}$ response.

These calculations show that it is possible for a transfer of $\mathrm{CO}_{2}$ from intermediate waters into deep waters to significantly affect atmospheric carbon dioxide by eliciting an alkalinity response. The most effective way to do this is to remineralize more organic matter in the deep ocean. It is also possible to obtain a response by altering wind-driven upwelling, but the magnitude (and even the direction) of the response to this mechanism depends strongly on the assumed regeneration function.

While the calculations show that it is possible to maintain polar preformed phosphorus constant despite a fall in intermediate phosphorus concentations, it is not obvious why the ocean should adopt the configuration required to achieve this stability. In the model, the effect is achieved by altering the mix of zero-P warm surface water and higher-P intermediate water flowing into the polar boxes. Intermediatedepth nutrient depletion could serve as a mechanism to deplete Antarctic preformed nutrients, and it offers a potential mechanism for the preformed phosphorus response to amplify the $\mathrm{CO}_{2}$ change due to the alkalinity response.

\section{Deep Sea Oxygen}

The consequences of the vertical chemical reorganization on the oxygen content of intermediate and deep waters are predicted by the equilibrium models. In the absence of major changes in ocean temperatures, the nutrient redistribution proposed above will change oxygen levels by about 80-100 $\mu \mathrm{mol} / \mathrm{kg}$. Hence, in the preglacial ocean, intermediate oxygen levels would rise to $190-210 \mu \mathrm{mol} / \mathrm{kg}$, and deep ocean concentrations would fall to $90-100 \mu \mathrm{mol} / \mathrm{kg}$. The oxygen crisis that occurs in previous models is averted. Only in the most oxygen depleted deepwaters of the ocean would nearanoxia occur. The oxygen content of the Panama Basin is $115 \mu \mathrm{mol} / \mathrm{kg}$, so these waters would approach oxygen depletion. If the deep waters of the ocean were about $2^{\circ} \mathrm{C}$ cooler [Shackleton and Chappell, 1986], then the deepwater oxygen concentration of the Panama Basin during glacial times would have been $20-40 \mu \mathrm{mol} / \mathrm{kg}$. It may also help that the Panama Basin is rapidly $(\sim 50 \mathrm{yr})$ ventilated over a relatively shallow sill depth $(2920 \mathrm{~m})$ in the Ecuador Trench and may be influenced somewhat by higher intermediate water oxygen levels [Lonsdale, 1977].

While average deep ocean oxygen is not in danger of depletion during glacial times, this model predicts that the oxygen content of the deep ocean decreases significantly, and any sedimentary process which depends on the bottom water oxygen content should record this event. Using the model developed by Emerson [1985] the predicted decrease in deep water oxygen could account for the increased organic carbon content of Panama Basin sediments [Pedersen, 1983]. The predicted decrease in oxygen with depth might also account for the increase in organic carbon content with depth observed for glacial age sediments in the eastern equatorial Atlantic [Curry and Lohmann, 1983]. Another consequence of this model is that the oxygen content of the middepth ocean would have increased, so we would expect to find lower organic carbon contents in glacial-age sediments from intermediatedepth ocean cores (in regions where surface productivity did not increase). These changes also have implications for the sedimentary cycle of redox-sensitive elements such as manganese, which may explain the occurrence of correlations between sedimentary manganese and climate [Bostrom, 1970; Berger et al., 1983]. 
Table 4. Results of Box Model study

\begin{tabular}{|c|c|c|c|c|c|c|c|}
\hline & & $\mathbf{P}$ & $\mathrm{CO}_{2}$ & A1k & $\delta^{13} \mathrm{C}$ & $\mathrm{o}_{2}$ & $\mathrm{pCO}_{2}$ \\
\hline \multicolumn{8}{|c|}{ IG-I } \\
\hline Warm surface & & 0.00 & $19 \overline{925}$ & 2319 & 2.41 & 265 & 281 \\
\hline South polar surface & & 1.63 & 2149 & 2348 & 0.44 & 340 & 281 \\
\hline North polar surface & & 0.64 & 2118 & 2331 & 1.68 & 340 & 257 \\
\hline Intermediate & & 2.09 & 2255 & 2357 & 0.02 & 65 & \\
\hline $\begin{array}{l}\text { Deep } \\
\Delta \delta^{13} \mathrm{C}(\mathrm{P}-\mathrm{B})\end{array}$ & & 2.19 & 2280 & 2390 & $\begin{array}{r}-0.06 \\
2.47\end{array}$ & 168 & \\
\hline \multicolumn{8}{|l|}{$\Delta 0-0(2-D)$} \\
\hline Warm surface & & 0.00 & 1925 & 2319 & 2.42 & 265 & 281 \\
\hline South polar surface & & 1.63 & 2149 & 2348 & 0.44 & 340 & 281 \\
\hline North polar surface & & 0.64 & 2117 & 2331 & 1.68 & 340 & 255 \\
\hline Intermediate & & 2.10 & 2255 & 2357 & 0.01 & 65 & \\
\hline $\begin{array}{l}\text { Deep } \\
\Delta \delta^{13} \mathrm{C}(\mathrm{P}-\mathrm{B})\end{array}$ & & 2.18 & 2279 & 2390 & $\begin{array}{r}-0.05 \\
2.46\end{array}$ & 112 & \\
\hline \multicolumn{8}{|c|}{$\underline{\mathrm{G}-1}$} \\
\hline Warm surface & & 0.00 & 1974 & 2440 & 2.35 & 265 & 235 \\
\hline South polar surface & & 1.64 & 2219 & 2469 & 0.45 & 340 & 234 \\
\hline North polar surface & & 0.66 & 2188 & 2452 & 1.63 & 340 & 216 \\
\hline Intermediate & & 1.68 & 2258 & 2470 & 0.44 & 127 & \\
\hline $\begin{array}{l}\text { Deep } \\
\Delta \delta^{13} C(P-B)\end{array}$ & & 2.58 & 2378 & 2488 & $\begin{array}{r}-0.43 \\
2.78\end{array}$ & 118 & \\
\hline \multicolumn{8}{|c|}{$\mathrm{G}-2$} \\
\hline warm surface & & 0.00 & $\overline{1971}$ & 2427 & 2.37 & 265 & 241 \\
\hline South polar surface & & 1.67 & 2214 & 2457 & 0.41 & 340 & 240 \\
\hline North polar surface & & 0.67 & 2183 & 2439 & 1.62 & 340 & 222 \\
\hline Intermedi & & 1.72 & 2257 & 2457 & 0.41 & 123 & \\
\hline $\begin{array}{l}\text { Deep } \\
\Delta \delta^{13} C(P-B)\end{array}$ & & 2.54 & 2363 & 2474 & $\begin{array}{r}-0.40 \\
2.76\end{array}$ & 69 & \\
\hline \multicolumn{8}{|c|}{$\underline{\mathrm{G}-3}$} \\
\hline Warm surface & & 0.00 & $\overline{1955}$ & 2389 & 2.37 & 265 & 254 \\
\hline South polar surface & & 1.63 & 2192 & 2418 & 0.43 & 340 & 255 \\
\hline North polar surface & & 0.66 & 2160 & 2401 & 1.63 & 340 & 233 \\
\hline Intermediate & & 1.69 & 2236 & 2419 & 0.42 & 82 & \\
\hline $\begin{array}{l}\text { Deep } \\
\Delta \delta^{13} \mathrm{C}(P-B)\end{array}$ & & 2.56 & 2372 & 2482 & $\begin{array}{r}-0.40 \\
2.77\end{array}$ & 113 & \\
\hline \multicolumn{8}{|c|}{$\underline{G-4}$} \\
\hline warm surface & 0.00 & & 1940 & 2353 & 2.39 & 265 & 268 \\
\hline South polar surface & 1.66 & & 2171 & 2383 & 0.39 & 340 & 268 \\
\hline North polar surface & 0.67 & & 2141 & 2365 & 1.62 & 340 & 248 \\
\hline Intermedi & 1.72 & & 2225 & 2384 & 0.39 & 65 & \\
\hline $\begin{array}{l}\text { Deep } \\
\Delta \delta^{13} C(P-B)\end{array}$ & 2.53 & & 2358 & 2468 & $\begin{array}{r}-0.38 \\
2.76\end{array}$ & 37 & \\
\hline \multicolumn{8}{|l|}{$\Delta_{0}+-C(P-B)$} \\
\hline Warm surface & & 0.00 & 1958 & 2371 & 2.39 & 265 & 273 \\
\hline South polar surface & & 1.65 & 2189 & 2401 & 0.42 & 340 & 272 \\
\hline North polar surface & & .64 & 2157 & 2382 & 1.67 & 340 & 250 \\
\hline Intermediate & & 1.71 & 2243 & 2402 & 0.43 & 113 & \\
\hline $\begin{array}{l}\text { Deep } \\
\Delta \delta^{13} C(P-B)\end{array}$ & & 2.54 & 2341 & 2453 & $\begin{array}{r}-0.42 \\
2.80\end{array}$ & 139 & \\
\hline
\end{tabular}

Models are as follows: IG-1, interglacial model with low intermediate-deep (I-D) mixing and low deep $\mathrm{CaCO}_{3}$ diss.; IG-2, interglacial model with high I-D mixing and higher deep $\mathrm{CaCO}_{3}$ diss.; G-1, glacial model with higher deep organic regeneration only; low I-D mixing, low deep $\mathrm{CaCO}_{3}$ regeneration; $\mathrm{G}-2$, glacial model with higher deep organic regeneration only; high I-D mixing, high deep $\mathrm{CaCO}_{3}$ regeneration; G-3, glacial model with increased upwelling only; low I-D mixing, low deep $\mathrm{CaCO}_{3}$ regeneration; $\mathrm{G}-4$, glacial model with increased upwelling only; high I-D mixing, high deep $\mathrm{CaCO}_{3}$ regeneration; G-5, glacial model with NADW transformed into NAIW only; low I-D mixing, low deep $\mathrm{CaCO}_{3}$ regeneration. 


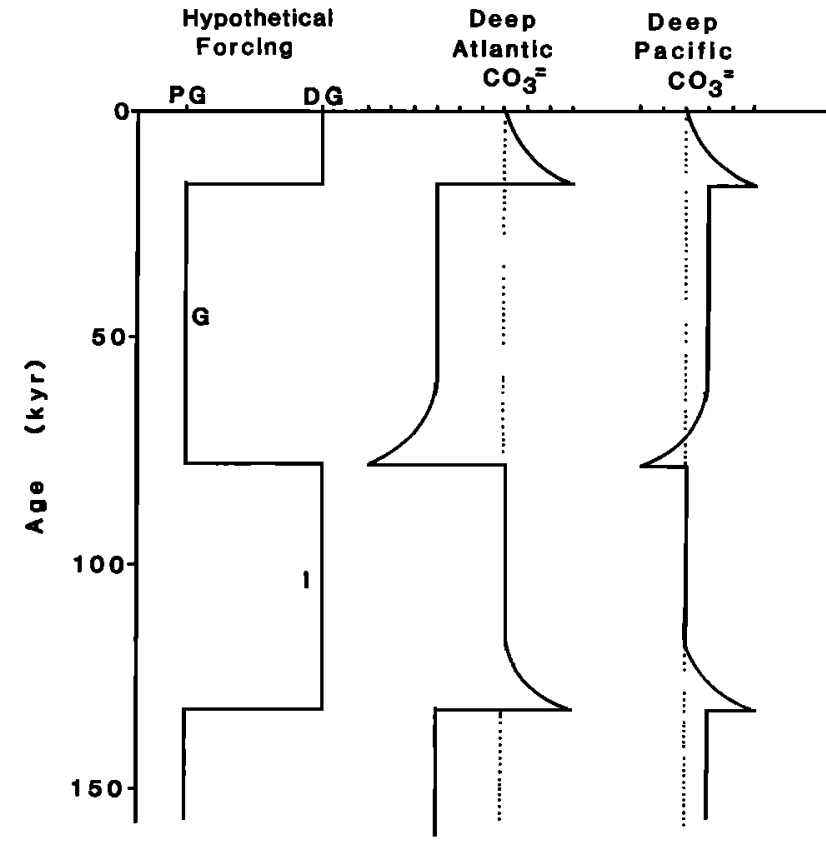

Fig. 7 Schematic drawing illustrating the carbonate ion response to hypothetical "100 kyr" square wave forcing. The dashed line indicates the "equilibrium interglacial" $\left[\mathrm{CO}_{3}=\right]$ position for both oceans. The responses are (1) an equilibrium response due to basin-basin transfers caused by reduction of North Atlantic Deep Water flow, (2) a transient response due to the intermediate-deep chemical transfers, and (3) the restoring equilibrium forcing which drives carbonate sedimentation back into balance.

\section{Late Quaternary Carbonate Dissolution Cycles}

Alkalinity and circulation changes predicted by this model have major implications for calcium carbonate sedimentation. In the modern ocean, carbonate preservation is enhanced in shallow sediments relative to deeper ones, because solubility increases with increasing pressure. Carbonate preservation is better in the Atlantic relative to the Pacific, because low- $\mathrm{CO}_{2}$ North Atlantic Deep Water is less corrosive to carbonate than high- $\mathrm{CO}_{2}$ Pacific Deep Water. Carbonate deposition in the Atlantic equals that deposited in the rest of the ocean [Turekian, 1965] even while containing only $25 \%$ of the total seafloor area [Menard and Smith, 1966]. In the steady state preglacial ocean, carbonate preservation is enhanced in the deep Pacific, and more dissolution occurs in the deep North Atlantic, because less $\mathrm{CO}_{2}$ is pushed into the deep North Pacific by North Atlantic Deep Water [Boyle and Keigwin, $1982,1985]$. In shallower cores, steady-state preservation is enhanced in both ocean basins, because of lower dissolved $\mathrm{CO}_{2}$ levels.

The carbonate preservation record is complicated by the alkalinity lag relative to the nutrient structure. Ignoring other factors that influence carbonate sedimentation, the following sequence of events is expected (Figure 7):

1. Immediately following the preglacial nutrient rearrangement, carbonate dissolution increases in the deep North Pacific and increases dramatically in the deep North Atlantic.

2. As the alkalinity of the ocean moves toward the new higher steady-state value, carbonate saturation increases everywhere in the ocean. After the rapid response to ocean circulation in the first step of this sequence, Pacific carbonate preservation becomes better than it was during late interglacial times. In the Atlantic, however, the initial dissolution pulse is followed by only slightly improved preservation, that is still worse than preservation during late interglacial times.

3. Immediately upon restoration of ocean circulation patterns to the deglacial mode, there is a preservation spike throughout the deep ocean, as acidic $\mathrm{CO}_{2}$ is moved out of the deep ocean into intermediate waters [Diester-Haas et al., 1973].

4. As oceanic alkalinity approaches the steady state deglacial level, dissolution increases throughout the ocean. In the deep Pacific, this extra dissolution results in poorer preservation than during late glacial times. But in the Atlantic, while preservation is poorer than it was immediately following the change in ocean circulation, it is better than it is during "glacial" periods, however.

The "lag" of Pacific carbonate sedimentation relative to climate change has been commented on previously [Moore et al., 1974] and attributed to the response time of the calcium carbonate system [Boyle, 1983], so the above scenario only belatedly provides a particular mechanism for this observation. The sequence of events is consistent with the evidence on deep Pacific dissolution provided by Keir and Berger [1985] (Figure 8). This new model provides more insight into Atlantic carbonate records. As Crowley [1983] has pointed out, over the last 140,000 years the most intense dissolution (in many parts of the Atlantic) occurred during oxygen isotope stage 4; this effect is expected when glaciation follows a long period of warm climate such as isotope stage 5. Furthermore, dissolution became quite a bit less severe during stage 3; this observation is in accord with Atlantic dissolution relaxation following alkalinity response combined with a return to oceanic conditions closer to the deglacial mode.

\section{Conclusion and Speculations}

Vertical rearrangement of oceanic chemical distributions is a potentially important mechanism for driving late Quaternary

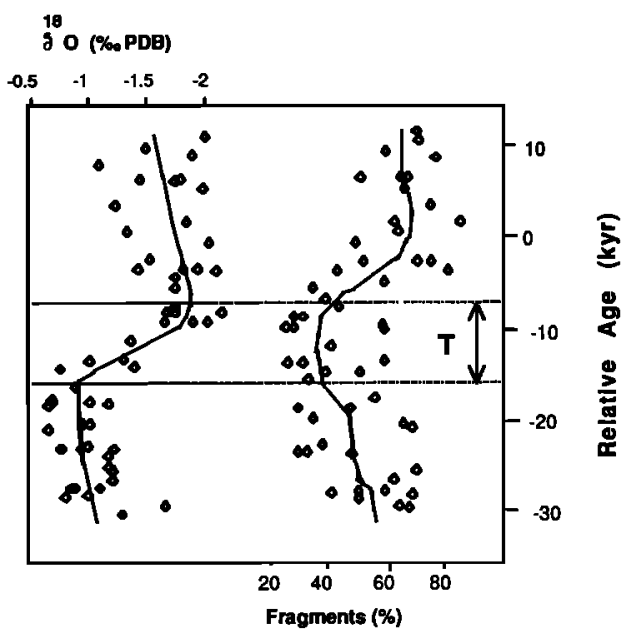

Fig. 8. Stacked $\delta^{18} \mathrm{O}$ and $\%$ fragments records from terminations in core V28-238, redrawn from Keir and Berger [1985]. Note that best preservation (fewer fragments, higher $\left[\mathrm{CO}_{3}=\right]$ ) occurs on the termination, followed by the most intense dissolution (greater fragmentation, lower $\left[\mathrm{CO}_{3}=\right]$ ) several thousand years after peak interglacial climate. This should be compared with the Pacific diagram from Fig. 7 but note that sense of direction is reversed in the two figures. 
glacial-interglacial $\mathrm{CO}_{2}$ fluctuations. Increasing oceanic alkalinity follows upon establishment of the deep- $\mathrm{CO}_{2}$-rich preglacial mode of the ocean. Since the alkalinity of the ocean takes several thousand years to respond to the change in oceanic nutrient structure, atmospheric $\mathrm{CO}_{2}$ lags significantly behind the oceanographic forcing. This alkalinity lag accounts for the phase lead of $\Delta \delta^{13} \mathrm{C}(\mathrm{P}-\mathrm{B})$ and $\mathrm{Cd}$ relative to $\mathrm{CO}_{2}$ and $\delta^{18} \mathrm{O}$. However, this mechanism can only account for changes in $\mathrm{CO}_{2}$ on the $10^{3}$ year time scale; more rapid variations would require some other mechanism.

What this model does not explain is why the ocean alternates between preglacial and deglacial modes. Since it has been established that there are strong statistical relationships between climate and Milankovitch-style orbital insolation variation, it seems likely that these insolation variations may somehow drive the ocean between modes. Exactly how orbital insolation would drive the ocean in this way is still a mystery. Future observations on the timing and geographic extent of intermediate and deep water nutrient contents should settle these questions.

\section{Appendix A: Five-Box Ocean Model}

The compositions of the warm surface box and the two cold polar boxes control atmospheric $\mathrm{CO}_{2}$. Two cold polar boxes are needed to represent polar waters similar to those of the modern North Atlantic (which are nutrient-impoverished), and those similar to the modern Antarctic (which are nutrientenriched). Although it is convenient to think of these two polar boxes as "Atlantic" (north polar surface) and "Antarctic" (south polar surface), there is no necessity for these water sources to be geographically restricted. In order to represent the transfer of nutrients from intermediate depths into the deep ocean, intermediate and deep ocean boxes are needed. In this model, the two ocean basins are not separated.This additional complication would be necessary for a full description of variability in the system along with some additional vertical resolution. The simplification was made deliberately to limit the number of free parameters.

Water fluxes between boxes are restricted in a few cases, partly based on oceanographic information and partly based on the desire to minimize the number of variables. It is assumed that water flows only from warm surface waters into cold polar waters, and not vice-versa; this a reasonable representation of the thermohaline character of high-latitude circulation. In view of data indicating that Antarctic polar surface nutrients did not change much, exchanges between intermediate and nutrient-enriched polar surface waters are adjusted to keep polar surface phosphorus constant. It is also assumed that deep water formation in polar regions is a oneway process; while there is an upwelling flux from intermediate waters into the polar oceans, there is no direct upwelling from the deep ocean into any of the surface boxes.

These simplifications and assumptions are not really necessary for functioning of the proposed mechanisms. The aim has been to keep the model as simple and determinate as possible, and to minimize arbitrary adjustments of variable parameters. The solutions adopted for the equilibrium extrema were arrived at by trial and error, seeking to maximize the resemblance of the equilibrium deglacial model to the modern ocean (GEOSECS data), and to produce the intermediate-todeep chemical fractionation in the equilibrium preglacial model. The solutions adopted here are not the only ones which can produce the intermediate-deep chemical fractionations, even given the structural constraints outlined here. Models
IG-1 and IG-2 illustrate this point. While the interbox fluctuations were chosen to be qualitatively defensible, they are not meant to be definitive descriptions of the ocean at any time. This uncertaintly should not be considered a deficiency, since the goal of this model is not to describe exactly how modern and glacial oceans function, but rather to illustrate the functioning and response times of processes that were of importance in controlling atmospheric $\mathrm{CO}_{2}$ fluctuations.

A feature of this box model which differs significantly from previous models lies in its treatment of the upwelling and downwelling into/from the warm surface box. Because the upper ocean is ventilated more by late winter convection than vertical physical mixing [Jenkins, 1980], the "warm surface water" that returns into the intermediate box is actually colder, and its gas content reflects that cooler temperature. In this model, it is assumed that the downwelling water is $17^{\circ} \mathrm{C}$ and has higher $\mathrm{CO}_{2}$ and $\mathrm{O} 2$ concentrations consistent with equilibration with the atmosphere at this temperature. Computationally, this is achieved for $\mathrm{CO}_{2}$ by withdrawing some $\mathrm{CO}_{2}$ from the upwelling intermediate water and placing it directly into the downwelling flux; for oxygen, it is achieved by specifying that oxygen in the the downwelling water is 265 $\mu \mathrm{mol} / \mathrm{kg}$. The waters in the cold surface box are assumed to have $340 \mu \mathrm{mol} / \mathrm{kg}$ of oxygen.

In addition to physical water circulation, chemical transfer processes were as follows:

1. All of the phosphorus upwelling into warm surface waters is removed through the formation of "Redfield" particulate matter whose composition is

\section{$\left(\mathrm{CH}_{2} \mathrm{O}\right)_{106}\left(\mathrm{NH}_{3}\right)_{16}\left(\mathrm{H}_{3} \mathrm{PO}_{4}\right)\left(\mathrm{CaCO}_{3}\right)_{21}$}

However, it is assumed that $20 \%$ of the $\mathrm{CaCO}_{3}$ formed "comes from" river input of dissolved $\mathrm{CaCO}_{3}$ and this fraction is sedimented onto the seafloor without dissolution.

2. This particulate matter is regenerated into intermediate and deep boxes with appropriate regeneration efficiencies ( $f_{1}$ for the intermediate box; $f_{2}$ for the deep box; $f$ values differ for organic matter [f(org)] and calcium carbonate [f(inorg)]). The $f$ efficiencies for organic matter are constrain by estimates for the vertical regeneration efficiencies of organic matter [Jenkins, 1980; Suess, 1980], and the $\mathrm{f}$ efficiency for $\mathrm{CaCO}_{3}$ is selected to give the correct modem intermediate-deep alkalinity distribution (as based on GEOSECS data [Takahashi et al., 1981]).

3. A correction for the effect of nitrate regeneration on alkalinity is made in the fashion outlined by Broecker [1982a,b].

4. No biological activity is included in the polar surface boxes, in part because the rate of biological production relative to physical turnover is low and in part because the effects of this process have been already discussed in published models and there is no need to investigate it here. The goal of this model is to illustrate a few processes which go on in the real world, not to exhaustively mimic the real world.

5. Gas exchange through the atmosphere is allowed to equilibrate the $\mathrm{pCO}_{2}$ between the surface boxes. Computationally, this is accomplished by shifting $\mathrm{CO}_{2}$ between the warm surface box and the cold polar boxes by the amount required to balance their $\mathrm{pCO}_{2}$. (Note: after this work was finished, a flaw was found in the algorithm used for $\mathrm{pCO}_{2}$. As a result, the north polar box always has $\mathrm{pCO}_{2}$ about $20 \mathrm{ppmV}$ lower than the other two surface boxes. Since this degree of disequilibrium is common in the modern ocean and since the revision would not change the solution 
significantly, it was not deemed worthwhile to redo the model).

6. Carbon isotopes are incorporated into the model assuming that organic carbon has $\delta^{13} \mathrm{C}=-22 \%$, that inorganic carbonate has $\delta^{13} \mathrm{C}$ equal to that of warm surface water, and that the $\mathrm{CO}_{2}$ which is transfered into the cold polar boxes is $1 \%$ o heavier than that of the warm surface box from which it comes. The latter assumption is chosen because the equilibrium carbon isotope composition at $2^{\circ} \mathrm{C}$ is $1 \%$ heavier than at $25^{\circ} \mathrm{C}$. The additional shift in the carbon isotope system due to this assumption is relatively minor.

7. Oxygen is incorporated into the model assuming that 138 oxygen molecules are consumed for every 106 organic carbon molecules regenerated. Takahashi et al. [1985] have recommended a higher value (170) for this ratio. The lower value was chosen, not because it necessarily is considered better than the newer estimate, but rather because a model of the structure given here results in too little oxygen in the "modern" ocean when the higher value is used. This problem could be due just as likely to deficiencies in the realism of this model as it is due to problems with the $\mathrm{O}_{2}$ :C Redfield ratio; this problem needs to be considered in more detail elsewhere. Cold surface waters are assumed to start with $340 \mu \mathrm{mol} / \mathrm{kg}$.

Given these assumptions and the structure of the model shown in Figure 5, the equations are determined, and it should not be necessary to list all of them here except for the example of the intermediate box ( $P=$ phosphorus concentration; $\mathbf{C}=$ $\mathrm{CO}_{2}$ concentration, $\mathrm{A}=$ alkalinity, $\delta=\delta^{13} \mathrm{C}, \mathrm{X}=$ oxygen).

The phosphorus balance for the intermediate box is

$$
\begin{aligned}
0=-\left(Q_{i-s}+Q_{i-n p}+Q_{i-s p}+Q_{i-d}\right) P_{i}+Q_{d-i} P d \\
+Q_{s p-i} P_{s p}+Q_{n p-i} P_{n p}+f_{l}(\text { org }) Q_{i-s} P_{i}
\end{aligned}
$$

.water fluxes ...regeneration...

The carbon balance for the intermediate box is

$$
\begin{aligned}
0=-\left(Q_{i-s}+Q_{i-n p}+Q_{i-s p}+Q_{i-d}\right) C_{i}+Q_{d-i} C_{d}+Q_{s p-i} C_{s p} \\
+Q_{n p-i} C_{n p}+Q_{s-i} C_{s}+\Delta C_{s} \\
+\left[106 f_{1}(\text { org })+17 f_{1}(\text { inorg) }) Q_{i-s} P_{i}\right.
\end{aligned}
$$

where $\mathrm{Q}_{\mathrm{i}-\mathrm{s}} \mathrm{P}_{\mathrm{i}}$ is the net organic phosphorus flux from the surface, 106 is the C:P Redfield ratio, 17 is the "dissolvable" $\mathrm{CaCO}_{3}: \mathrm{P}$ ratio, and $\Delta \mathrm{C}_{8}$ is the amount of carbon which must be added to maintain $\mathrm{pCO}_{2}$ when the $25^{\circ} \mathrm{C}$ warm surface water is cooled to $17^{\circ} \mathrm{C}$ before downwelling into the intermediate box. The alkalinity balance for the intermediate box is

$$
\begin{aligned}
0 & =-\left(Q_{i-s}+Q_{i-n p}+Q_{i-s p}+Q_{i-d}\right) A_{i}+Q_{d-i} A_{d}+Q_{s p-j} A_{s p} \\
& +Q_{n p-i} A_{n p}+Q_{s-i} A_{s}+\left[34 f_{1}(\text { inorg })-16 f_{1}(\text { org })\right] Q_{i-s} P_{i}
\end{aligned}
$$

where 34is 2 equiv. Alk per 17 moles of "dissolvable" $\mathrm{CaCO}_{3}$ and 16 is the number of acid equivalents released from the oxidation of 16 moles of $\mathrm{NH}_{3}$ (from the $\mathrm{N}: \mathrm{P}$ Redfield Ratio). The carbon isotope balance for the intermediate box is

$$
\begin{aligned}
0=-\left(Q_{i-s}+Q_{i-n p}+Q_{i-s p}+Q_{i-d}\right) C_{i} \delta_{i}+Q_{d-i} C_{d} \delta_{d}+Q_{s p-i} C_{s p} \delta_{s p} \\
+Q_{n p-i} C_{n p} \delta_{n p}+Q_{s-i} C_{s} \delta_{s}-(106)(22) f_{1}(\text { org) }) Q_{i-s} P_{i} \\
+17 f_{1} \text { (inorg) } \delta_{s}+\Delta C_{s} \delta_{s}
\end{aligned}
$$

where the 22 is the assumed carbon isotope composition of organic carbon. The oxygen balance for the intermediate box is

$$
\begin{aligned}
0= & -\left(Q_{j-s}+Q_{i-n p}+Q_{i-s p}+Q_{i-d}\right) X_{i}+Q_{d-i} X_{d} \\
& +340\left(Q_{s p-i}+Q_{n p-i}\right)+265 Q_{s-i}-138 f_{1}(o r g) Q_{i-s} P_{i}
\end{aligned}
$$

where 340 is the oxygen content of cold surface water, 265 is the oxygen content of $17^{\circ} \mathrm{C}$ surface water, and 138 is the assumed $\mathrm{O}_{2}: \mathrm{P}$ Redfield ratio.

The model was solved first by using the matrix inversion function of a microcomputer spreadsheet and then by an iterative finite difference approach (to verify the accuracy of the spreadsheet inversion routine).

\section{Appendix B: The Vertical Regeneration Cycle of $\mathrm{CaCO}_{3}$}

The vertical distribution of alkalinity and dissolved carbon dioxide is determined by a balance between (1) the vertical regeneration functions of sinking organic debris and $\mathrm{CaCO}_{3}$ and (2) the intensity of mixing between intermediate and deep waters. It is believed that most organic matter sinking out of the euphotic zone decomposes in the upper ocean (about 85\%). This belief is based on models of oxygen consumption in the upper ocean [Jenkins, 1980] and fluxes estimated by sediment traps [Suess, 1980]. It is generally assumed that $\mathrm{CaCO}_{3}$ is returned into solution deep in the water, perhaps dominantly by dissolution on the seafloor. The flux of organic carbon out of the euphotic zone is higher than that of inorganic carbonate, but sediment traps deployed in the deep ocean generally show $\mathrm{C}_{\text {org }}$ : $\mathrm{CaCO}_{3}$ ratios close to $1: 1$ (see data summarized by Dymond and Lyle, [1985], due to the preferential degradation of organic carbon relative to carbonate. The vertical profile of alkalinity shows a deep maximum than phosphorus and is consistent with a deeper regeneration cycle [Edmond, 1974]. Neither line of evidence concerning the relative efficiency of organic and inorganic regeneration rules out significant calcium carbonate dissolution during descent through the water column. Because the collection efficiency of shallow traps is uncertain (because of artifacts created by hydrodynamic effects and "swimmers"), changes in the vertical flux of $\mathrm{CaCO}_{3}$ are not easily established.

The observed alkalinity and dissolved carbon dioxide profiles could be generated with quite different vertical regeneration functionalities. The simplest illustration of this point can be made with a two-box model. Fluxes of water (Q) between the intermediate and deep boxes must be equal. In the euphotic zone of the upper box, organisms transform dissolved elements into a flux of particulate phosphorus ( $\mathrm{F}_{\mathrm{P}}$ ), organic carbon (106FP) (denoted by " $O$ " subscript), and inorganic calcium carbonate (21FP) (denoted by "I" subscript). Some of this sinking particle flux dissolves in the upper box (1-fo-d, 1- $\left.f_{I-d}\right)$, some dissolves in the deep box $\left(f_{O-d}, f_{I-d}\right)$, and some of the carbonate is permanently removed from the system into sediments ( $5 \mathrm{FP}_{\mathrm{P}}$, which is taken as equal to the influx of calcium carbonate from rivers into the upper box). The mass balance equations for dissolved carbon dioxide (C) and alkalinity (A) determine two linearly independent equations for this system (written here for the deep box; the equations for the upper box are dependent and differ only by sign inversion):

$$
\begin{gathered}
16 F_{P} f_{I-d}+106 F_{P} f_{O-d}+Q\left(C_{u}-C_{d}\right)=-116 F_{P} \\
32 F_{P} f_{I-u}+Q\left(A_{u}-A_{d}\right)=-32 F_{P}
\end{gathered}
$$


production ( $\left.F_{P}\right)$ as constraints to be fulfilled, there are three unknowns in two equations. If we presume to know the fraction of organic matter regenerated in the deep box (fo-d), then the possible set of solutions to the system trades off changes in the interbox fluxes $(Q)$ against the changes in the fraction of inorganic carbonate redissolved in the deep box $\left(f_{I-d}\right)$. In this system, there are many possible solutions consistent with given vertical distributions of dissolved carbon dioxide and alkalinity. One extreme of this set invokes rapid interbox fluxes and a higher fraction of calcium carbonate dissolution in the deep box, and the other extreme invokes slow interbox fluxes and a lower fraction of calcium carbonate dissolution in the deep box.

This simple model illustrates a principle applicable to more complex models: one cannot tell the difference between calcium carbonate and carbon dioxide molecules that have been regenerated within a box and those that have been mixed into the box. This point is illustrated with scenarios from the more complex model in the main body of this paper (IG-1 and IG-2). Independent lines of evidence can overcome this uncertainty (e.g. sediment traps, measurements of carbonate dissolution on the seafloor, or physical evidence on intermediate-deep mixing rates), but the present state of knowledge allows one to presume a range of regeneration functions. Other authors have chosen to assume that all calcium carbonate regeneration occurs on the seafloor [Dymond and Lyle, 1985; Sarmiento et al., 1988].

Acknowledgments. I thank Laurent Labeyrie for stimulating discussions and for providing the foraminifera from MD80304. Rob Toggweiler, Alan Mix, Wally Broecker, Nick Shackleton, and Tom Pedersen contributed further helpful comments regarding this idea. This paper grew out of work sponsored by NSF grant OCE8411141.

\section{References}

Barnola, J. M., D. Raynaud, A. Neftel, and H. Oeschger, Comparison of $\mathrm{CO}_{2}$ measurements by two laboratories on air from bubbles in polar ice, Nature, 303, 410-413, 1983.

Barnola, J. M., D. Raynaud, Y. S. Korotkevitch, and C. Lorius, Vostok ice core, a 160,000-year record of atmospheric $\mathrm{CO}_{2}$, Nature, 329, 408-414, 1987.

Berger, W. H., R. C. Finkel, J. S. Killingley, and V. Marchig, Glacial-Holocene transition in deep-sea sediments: Manganese spike in the east-equatorial Pacific, Nature, 303, 231-233, 1983.

Bishop, J. K., R. W. Collier, D. R. Ketten, and J. M. Edmond, The chemistry, biology, and vertical flux of particulate matter from the upper $1500 \mathrm{~m}$ of the Panama Basin, Deep Sea Res. Part A. , 27, 615-640, 1980.

Bostrom, K., Deposition of manganese rich sediments during glacial periods, Nature, 226, 629-630, 1970.

Boyle, E. A., Chemical accumulation variations under the Peru current during the past 130,000 years, J. Geophys. Res. 88, 7667-7680, 1983.

Boyle, E., Deep ocean circulation, preformed nutrients, and atmospheric carbon dioxide: theories and evidence from oceanic sediments, in Mesozoic and Cenozoic Oceans, Geodyn. Ser, vol.15, edited by K. J. Hsu pp. 49-60, AGU, Washington D.C., 1986.

Boyle, E. A., Vertical oceanic nutrient fractionation and glacial/interglacial $\mathrm{CO}_{2}$ cycles, Nature, 331, 55-56, 1988.

Boyle, E. A., and L. D. Keigwin, Comparison of Atlantic and Pacific paleochemical records for the last 250,000 years: changes in deep ocean circulation and chemical inventories, Earth Planet. Sci. Lett., 76, 135-150, 1985.
Boyle, E., and L. D. Keigwin, Glacial North Atlantic hydrōgraphy and atmospheric carbon dioxide (abstract), EOS Trans. AGU, 67, 868-869, 1986.

Boyle, E., and L. D. Keigwin, North Atlantic thermohaline circulation during the last 20,000 years linked to high latitude surface temperature, Nature. 330, 35-40, 1987.

Broecker, W. S., Glacial to interglacial changes in ocean chemistry, Prog. Oceanogr, 11, 151-197, 1982.

Broecker, W. S., Ocean chemistry during glacial time, Geochim. Cosmochim. Acta 46, 1689-1705, 1982.

Broecker, W. S., and T. H. Peng, Global carbon cycle: 1985 , Radiocarbon , 28, 309-327, 1986.

Broecker, W. S., and T. H. Peng, The role of $\mathrm{CaCO} 3$ compensation in the glacial to interglacial $\mathrm{CO}_{2}$ change, Global Biogeochem. Cycles, 1, 15-30, 1987.

CLIMAP project members, The last interglacial ocean, Quat. Res., 21, 23-124, 1984.

Cofer-Shabica, N., and L. Peterson, Caribbean carbon isotope record for the last 300,000 years, Geol. Soc. Am. Abstr. with programs, $18,567,1986$.

Crowley, T. J., Calcium carbonate preservation patterns in the central North Atlantic during the last 150,000 years, Mar. Geol., 51, 1-14, 1983.

Curry, W. B., and T. J. Crowley, C-13 in equatorial Atlantic surface waters: implications for ice age $\mathrm{pCO}_{2}$ levels, Paleoceanography, 2 , 489-531, 1987.

Curry, W., and G. P. Lohmann, Reduced advection into Atlantic Ocean deep eastern basins during last glaciation maximum, Nature, 306, 577-580, 1983.

Diester-Haas, L., H.-J. Schrader, and J. Thiede, Sedimentological and paleoclimatological investigations of two pelagic ooze cores off Cape Barbas, North-West Africa, Meteor Forschungsergebr. Reike C, 7, 19-66, 1973.

Duplessy, J. C., N. J. Shackleton, R. G. Fairbanks, L. Labeyrie, D. Oppo, and N. Kallel, Deep water source variations during the last climatic cycle and their impact on the global deep water circulation, Paleoceanography, 3, 343-360, 1988.

Dymond, J., and M. Lyle, Flux comparisons between sediments and sediment traps in the eastern tropical Pacific: Implications for atmospheric $\mathrm{CO}_{2}$ variations during the Pleistocene, Limnol. Oceanogr., 30, 699-712, 1985.

Edmond, J. M., On the dissolution of carbonate and silicate in the deep ocean , Deep Sea Res., 21, 455, 1974.

Edmond, J. M., and J. M. Gieskes, On the calculation of the degree of seawater with respect to calcium carbonate under in-situ conditions, Geochim. Cosmochim. Acta, 34,12611291, 1970.

Emerson, S., Organic carbon preservation in marine sediments in Natural Variations in Carbon Dioxide and the Carbon Cycle, Archean to Present, Geophys. Monogr. Ser., vol. 32, edited by E. T. Sundquist and W. S. Broecker, pp. 78-88, AGU, Washington, D.C., 1985.

Hansen, J., A Lacis, G. Russel, T.P. Stone, I. Fung, R. Rued, and J. Levre, in Climate sensitivity: analysis of feedback mechanisms, Geophys. Monogr. Ser, vol. 29, edited by J.E. Hansen and T. Takahashi, pp. 130-163, AGU, Washington, D.C. 1984.

Jenkins, W. J., Tritium and He-3 in the Sargasso Sea, J.Mar. Res. 38, 533-569, 1980.

Kallel, N., L. D. Labeyrie, A. Juillet-Laclerc, and J.C. Duplessy, A deep hydrological front between intermediate and deep water masses in the glacial Indian Ocean, Nature, 333, 651-655, 1988. 
Keigwin, L. D., North Pacific Deep Water formation during the latest glaciation, Nature, 330, 362-364, 1987.

Keir, R. S., and W. H. Berger, Late Holocene carbonate dissolution in the equatorial Pacific: Reef Growth or Neoglaciation? in Natural Variations in Carbon Dioxide and the Carbon Crcle. Archean to Present. Geophys. Monogr. Ser, vol. 32, edited by E. T. Sundquist and W. S. Broecker, pp. 208-220, AGU, Washington, D.C., 1985.

Knox, F., and M. McElroy, Changes in atmospheric $\mathrm{CO}_{2}$ : Influence of biota at high latitudes, J. Geophys. Res., 89 , 4629-4637, 1984.

Labeyrie, L. D., and J.-C. Duplessy, Changes in oceanic $13 \mathrm{C} / 12 \mathrm{C}$ ratio during the last 140,000 years: high latitude surface water records, Palaeogeog. Palaeoclimatol. Palaeoecol., 50, 217-240, 1985.

Lonsdale, P., Inflow of bottom water to the Panama Basin, Deep Sea Res. 24, 1065-1101, 1977.

Martin, J. H., and R. M. Gordon, Northeast Pacific iron distributions in relation to phytoplankton productivity, Deep Sea Res., 35, 177-196, 1988.

Martin, J. H., and S. E. Fitzwater, Iron deficiency limits phytoplankton growth in the north-east Pacific subarctic, Nature, 331, 341-343, 1988.

Menard, H. W. and S. M. Smith, Hypsometry of ocean basin provinces, L. Geophys. Res,.71, 4305-4326, 1966.

Millero, F., The thermodynamics of the carbonate system in seawater, Geochim. Cosmochim. Acta 43, 1651-1661, 1979.

Mix, A., and N. J. Shackleton, d13C analyses of foraminifera and atmospheric $\mathrm{pCO}_{2}$ variations, paper presented at the 2nd International Conference on Paleoceanography. Abstracts, Woods Hole, 1986.

Moore, T. C., N. G. Pisias and G. R. Heath, Climate changes and lags in Pacific carbonate preservation, sea surface temperature, and global ice volume, in The Fate of Fossil Fuel $\mathrm{CO}_{2}$, edited by N. Andersen and A. Mallahof, pp. 145-165, Plenum Press, New York, 1974.

Neftel, A., H. Oeschger, J. Schwander, B. Stauffer, and R. Zumbrunn, Ice core sample measurements give atmospheric $\mathrm{CO}_{2}$ content during the last 40,000 years, Nature. 295, 220-223, 1982.

Neftel, A., E. Moor, H. Oeschger, and B. Stauffer, Evidence from polar ice cores for the increase in atmospheric $\mathrm{CO}_{2}$ in the past two centuries, Nature, 315, 45-47, 1985.

Neftel, A., H. Oeschger, T. Staffelbach, and B. Stauffer, $\mathrm{CO}_{2}$ record in the Byrd ice core 50,000-5,000 years BP, Nature, 331, 609-611, 1988.

Oeschger, H., J. Beer, U. Siegenthaler, B. Stauffer, W. Dansgaard, and C.C. Langway, Late glacial climate history from ice cores, in Climate sensitivity: analysis of feedback mechanisms, Geophys. Monogr. Ser., vol. 29, edited by J.E. Hansen and T. Takahashi, pp. 299-306, AGU, Washington, D.C. 1984.

Oeschger, H., B. Stauffer, R. Finkel, and C. C. Langway, Variations of the $\mathrm{CO}_{2}$ concentration of occluded air and of anions and dust in polar ice core, in Carbon Dioxide and the Carbon Cycle. Archean to Present Geophys. Monogr. Ser., vol. 32, edited by E. T. Sundquist and W. S. Broecker, pp. 132-142, AGU, Washington, D.C., 1985.

Oppo, D., and R. G. Fairbanks, Variability in the deep and intermediate water circulation of the Atlantic Ocean during the past 25,000 years: Northern hemisphere modulation of the Southern Ocean, Earth Planet. Sci. Lett., 86, 1-15, 1987.

Pedersen, T. F., Increased productivity in the eastern equatorial Pacific during the last glacial maximum $(19,000$ to 14,000 yr B.P.), Geology, 11, 16-19, 1983.

Pedersen, T. F., M. Pickerzing, J. S. Vogel, J. N. Southon, and D. E. Nelson, The response of benthic foraminifera to productivity cycles in the eastern Equatorial Pacific, faunal and geochemical constraints on glacial bottom-water oxygen level, Paleoceanography, 3, 157-168, 1988.

Sarmiento, J. L., and J. R. Toggweiler, A new model for the role of the oceans in determining atmospheric $\mathrm{pCO}_{2}$, Nature, 308, 621-624.

Sarmiento, J. L., J. R. Toggweiler, and R. Najjar, Ocean carbon cycle dynamics and atmospheric $\mathrm{CO}_{2}$, Proc. Roy. Soc. London. 325, 3-21, 1988.

Shackleton, N. J., Formation of bottom water in the glacial North Pacific (abstract), EOS Trans. AGU, 66, 292, 1985.

Shackleton, N. J., and J. Chappell, Oxygen isotopes and sea level, Nature, 324, 137-140, 1986.

Shackleton, N. J., and N. G. Pisias, Atmospheric carbon dioxide, orbital forcing, and climate, in Carbon Dioxide and the Carbon Cycle. Archean to Present. Geophys. Monogr. Ser. vol. 32, edited by E. T. Sundquist and W. S. Broecker, pp. 313-318, AGU, Washington, D.C., 1985.

Shackleton, N. J., M. A. Hall, J. Line, and C. Shuxi, Carbon Isotope data in core V19-30 confirm reduced carbon dioxide concentration in the ice age atmosphere, Nature, 306, 319-322, 1983.

Siegenthaler, U., and T. Wenk, Rapid atmospheric $\mathrm{CO}_{2}$ variations and ocean circulation, Nature, 308, 624-625, 1984.

Suess, E., Particulate organic carbon flux in the oceanssurface productivity and oxygen utilization, Nature. 288, 260-263, 1980.

Takahashi,, T., W. S. Broecker, and A. E. Bainbridge, Supplement to the alkalinity and total carbon dioxide concentration in the world oceans, in Carbon Cycle Modelling, edited by B. Bolin, Scope 16, WileyInterscience, New York, 1981.

Takahashi, T., W. S. Broecker, and S. Langer, Redfield ratio based on chemical data from isopycnal surfaces, J. Geophys. Res., 90, 6907-6924, 1985.

Turekian, K. K., Some aspects of the geochemistry of marine sediments, in Chemical Oceanography, 1st ed., edited by J. P Riley and G. P. Skirrow), pp. 81-126, Academic Press, London, 1965.

Zahn, R., K. Winn, and M. Sarnthein, Benthic foraminiferal ${ }^{13} \mathrm{C}$ and accumulation rates of organic carbon: Uvigerina peregring group and Cibicidoides wuellerstorfi, Paleoceanography 1, 27-42, 1986.

Zahn, R., M. Sarnthein, and H. Erlenkeuser, Benthic isotope evidence for changes of the Mediterranean outflow during the late Quaternary, Paleoceanography, 2, 543-560, 1987.

E.A. Boyle, Department of Earth, Atmospheric, and Plantary Sciences, Room E34-258, Massachusetts Institute of Technology, Cambridge, MA 02139.

(Received October 13, 1987; accepted January 15, 1988.) 